\title{
Las Casas de Sal: espacialidad y afecto en las memorias de las infancias en el exilio
}

\section{Fira Chmiel ${ }^{1}$}

Recibido: 14 de febrero de 2020 / Aceptado: 19 de junio de 2020

Resumen. En este texto presento algunos avances de mi investigación doctoral en curso, en la que exploro, desde una perspectiva biográfica, las memorias de quienes tuvieron la experiencia de haber sido niños y niñas durante el exilio forzado de las últimas dictaduras en Uruguay y en Argentina. En esta oportunidad, me centro en indagar algunas articulaciones sobre memoria, espacio e infancia, que emergen de los recuerdos de "aquellos" niños y niñas. En particular, en la casa como espacio en el que se conjugan diversos sentidos y formas iniciales de vínculo e intimidad. Estos recuerdos puestos en relato, abren nuevos accesos para comprender no solo el lugar de los niños y niñas de entonces en el los tránsitos del exilio, sino también, los sentidos que se son reelaborados en el presente.

Palabras clave: Infancia; exilio; memoria; espacialidad.

\section{[pt] As Casas de Sal: espacialidade e afetividade nas lembranças das infâncias no exílio}

Resumo. Neste texto, apresento alguns avanços em minha pesquisa de doutorado em andamento, na qual exploro, de uma perspectiva biográfica, as memórias daqueles que tiveram a experiência de ter sido crianças durante o exílio forçado das últimas ditaduras no Uruguai e na Argentina. Nesta ocasião, concentro-me em investigar algumas articulações sobre memória, espaço e infância, que emergem das memórias dessas "crianças". Em particular, na casa como um espaço no qual vários sentidos e formas iniciais de vínculo e intimidade são combinados. Essas memórias contadas abrem novos acessos para entender não apenas o lugar das crianças daquela época nos trânsitos do exílio, mas também os sentidos que são retrabalhados no presente.

Palavras chave: Infância; exílio; memória; espacialidade.

\section{[en] The Salt Houses: Spatiality and Affection in the Memories of Childhoods in Exile}

Abstract. In this text I present some progress in my ongoing doctoral research, in which I explore, from a biographical perspective, the memories of those who had the experience of having been children during the forced exile of the last dictatorships in Uruguay and Argentina. In this opportunity, I focus on investigating some articulations on memory, space and childhood, which arise from the memories of "those" children. In particular, in the house as a space where several meanings and initial forms of bond and intimacy are combined. These related memories open new accesses to understand not only the place of the children of that time in the transits of exile, but also the senses that are reworked in the present.

Keywords: Childhood; exile; memory; spatiality.

Sumario. 1. Introducción. 2. Metodología. 3. El sabor de la experiencia. Debates sobre la dimensión generacional de la memoria en el Cono Sur. 4. Infancia y dictadura. 5. Espacios, territorios y pertenencias. 6. Migas de pan: la memoria como retorno. 7. Las casas y el (im)posible retorno. 8. Mudanzas salobres: nuevas pertenencias. 9. Pequeñas escenas de gestos domésticos. 9. Para el cierre. 10. Referencias bibliográficas.

Cómo citar: Chmiel, F. (2020): Las Casas de Sal: espacialidad y afecto en las memorias de las infancias en el exilio, Sociedad e Infancias, 4, 111-122.

\footnotetext{
LICH-CONICET, CEDESI-EH, UNSAM, Argentina.

E-mail: firach@gmail.com
} 


\section{Introducción}

En "La casa de azúcar" Ocampo (1982) crea un relato donde la figura de la casa se transforma en un espacio inquietante. El cuento nos propone una alegoría que tensiona la relación entre el espacio y la identidad: habitar la casa supone habitar la personalidad de alguien precedente. Me interesó pensar en la metáfora de la casa de azúcar y tomar la idea de la evanescencia, como efecto de la itinerancia presente en los recuerdos vaporosos de aquellos niños y niñas que experimentaron el exilio de las últimas dictaduras. Más que la dulzura inquietante del azúcar es, tal vez, la sal, quien aporte su sabor metafórico a estas casas. Es la materia en que se convierte quien mira hacia atrás, como la esposa de Lot al volver su mirada sobre su ciudad en llamas. La huida como salvación comprende el riesgo de "mirar" hacia atrás, algo que también sucede en el mito de Orfeo y Eurídice. Los cristales de sal tienen la propiedad de habilitar la permanencia y la conservación de los alimentos, como pueden preservarse también los recuerdos. Es el sabor de la emoción y de la lágrima. Es el gusto del espacio al que no se vuelve. La pérdida (¿inevitable?), el gesto advertido.

En este texto presento algunos avances de mi investigación doctoral en curso, en la que exploro, desde una perspectiva biográfica, las memorias de quienes tuvieron la experiencia de haber sido niños y niñas durante el exilio forzado de las últimas dictaduras en Uruguay y en Argentina. Recupero de los relatos de vida la dimensión espacial de la experiencia infantil recordada, en especial, al lugar de la casa como escena pregnante. Allí se despliegan las oscilaciones de la pertenencia, las tramas afectivas de los recuerdos sobre los espacios y las casas de los niños y niñas de entonces.

\section{Metodología}

El enfoque biográfico ofrece instrumentos teóricos y metodológicos para el ingreso al terreno de la textura subjetiva. Permite atender a las formas en que las experiencias singulares se articulan con los procesos históricos y sociales que conforman una subjetividad particular.

Tal como sostiene Delory-Momberger (2012), la mirada biográfica se enfoca en comprender la relación singular que el individuo mantiene, en su actividad biográfica, con el mundo histórico y social. Habilita a explorar las experiencias subjetivas, entendidas no como aquello que los individuos "tienen" sino atendiendo a que son los sujetos quienes se constituyen por medio de la experiencia (Scott, 2001). Dentro de las orientaciones que formula esta perspectiva atiendo al nivel socio-simbólico de análisis (Bertaux, 1999) ya que aborda objetos que contemplan actitudes, representaciones, las voces de los sujetos para comprender los significados que configuran su experiencia (Bertaux, 1999). Como exploro en los pespuntes de la experiencia y me pregunto por los sentidos que desde el presente se elaboran sobre las memorias de infancia, esta mirada analítica me permite ahondar en los bordes entre la filigrana subjetiva y el andamiaje social.

En esta articulación, atiendo a los relatos de vida cuyo lugar en el paradigma biográfico es central, ya que en ellos se articula "el relato individual, los hábitos, los moldes narrativos, los diversos estereotipos y los diferentes tipos de memoria que he evocado" (Robin, 1989: 33). Los silencios, los olvidos también son constitutivos del relato, así como los son los aspectos transmitidos, que "ponen de manifiesto el encuadramiento del que es objeto y los diferentes modelos identificatorios que lo constituyen". De esta manera, los relatos de vida son claves, según Robin, para comprender cómo se construye la "novela memorial". ${ }^{2}$ Así, realicé entrevistas biográficas ${ }^{3}$ pues tienen como finalidad recolectar y oir, en su singularidad, la voz de una persona en un momento de su existencia y de su experiencia (Conde, 1994). Y tal como propone Dutrenit (2015), considero para entrevistar tanto a quienes han nacido en los lugares de acogida como a quienes han migrado siendo niños y niñas en edad escolar (previo a la escuela secundaria), durante los períodos dictatoriales en Argentina (1976-1983) y Uruguay (1973-1985). En cuanto al análisis, recurro al recurso de las escenas (Paiva, 2018; 2006) en tanto herramienta para organizar los recuerdos. Este recurso se detiene en las descripciones densas, los sentidos que configuran la experiencia puesta en relato.

En lo que sigue del texto, intentaré ahondar en algunas escenas relativas a la dimensión espacial que emergen de los recuerdos de "aquellos" niños y niñas. En particular, en la casa como espacio en el que se conjugan diversos sentidos y formas iniciales de vínculo. La peculiaridad fragmentaria de la memoria nos orienta a atender al espacio cotidiano como lugar en el que se desarrollan las tramas afectivas, se despliegan las primeras modalidades de vínculo, de relación con la intimidad, el lugar donde se construye el sentimiento de familiaridad. Algunos tránsitos en los que se anclan los recuerdos, conectan lugares en líneas rectas. Otros ofrecen figuras triangulares y varios relatos diseñan su propia y enmarañada figura de tránsitos. Para algunos, los trazos de estos recorridos, son reconstruidos o imagi-

Robin (1989) retoma la noción de "novela familiar" formulada por Freud y recupera su "aspecto fantasmático de la elaboración de la construcción, su aspecto novelesco, de relato o de escenificación y su relación con el origen, con el pasado" (p. 69).

Realicé desde marzo del 2019 hasta el momento, cuarenta y dos entrevistas (de una duración de dos horas aproximadas), veintitrés a quienes han nacido en familias exiliadas de origen argentino y diecinueve exiliadas de origen uruguayo. Del total, ocho de los entrevistados viven actualmente en el exterior mientras que el resto residen actualmente en Uruguay o en Argentina. Algunos de los entrevistados han nacido en los países del exilio familiar, otros partieron durante su primera infancia y otros migraron en edad escolar. Asimismo, los países de acogida han sido diversos, privilegiando la heterogeneidad de experiencias y tránsitos sociales y culturales. Los nombres de los entrevistados que aquí aparecen son algunos verdaderos y otros de fantasía, según sus preferencias al momento de ser consultados. Muchas localizaciones específicas fueron modificadas a fin de no exponer sus identidades. 
nados a través de los relatos familiares. Todos estos diseños se configuran como posibles "fragmentos de conexión" (Philo, 2003) a ser explorados.

\section{El sabor de la experiencia. Debates sobre la dimensión generacional de la memoria en el Cono Sur}

Dentro del campo estudios interdisciplinarios sobre la memoria, el trabajo que sigue se enfoca en discusión sobre la experiencia generacional de los traumas sociales. Desde allí recuperamos diferentes interrogantes que integran la perspectiva generacional de los estudios de la memoria en la región.

Por una parte, emerge la pregunta por el cómo contar y el carácter narrativo de la experiencia biográfica, tal como nos propone Arfuch. La singularidad de propuestas narrativas que proponen las segundas generaciones en el exilio, plantea la pregunta sobre los bordes difusos que ofrecen los géneros discursivos. ¿Cómo caracterizar estas nuevas narrativas que fusionan ficción y los hechos históricos? ¿Biografía, autobiografía, ficción, memoria, poesía, imaginación? A la vez, Arfuch (2008) señala la emergencia de producciones desde un tiempo propio: "el tiempo de los hijos". En línea con los trabajos de Arfuch, atendiendo a los vínculos entre arte, memoria y política numerosos trabajos analizan producciones de las segundas generaciones (Basile, 2019; Daona, 2017; Logie, I. y Willem B., 2016, entre múltiples autores) vinculando la pregunta por la memoria con la crítica cultural o literaria. Entre ellos los trabajos de Alberione (2018) y Bassa (2016) abordan las producciones simbólicas de las segundas generaciones del exilio.

Otro grupo de investigaciones se interroga por el orden de la experiencia o el carácter de la experiencia de las segundas generaciones con relación a una experiencia "originaria". Nacido de los aportes de Hirsch (2008) y su noción de "posmemoria" (que reflexiona sobre las generaciones de los hijos de las víctimas del Holocausto), este debate cruza el océano para pensarse en las memorias sobre la historia reciente del Cono Sur (Ros, 2012; Serpente, 2011; Kaiser, 2005), o también en tanto memorias "intermedias" como 1,5 (Levey, 2014; Suleiman, 2002). Esta propuesta no se encuentra exenta de críticas, como la de Sarlo (2005), quien discute la especificidad fragmentaria, mediada y subjetiva de la noción, entendiendo que son aspectos que hacen a las características de la memoria como tal. Considera, además, otros aspectos que modifican las maneras de interpretar el pasado más que la dimensión generacional. Para la autora, aquello distintivo de lo "post" no es su instancia posterior sino su posición subjetiva en los eventos relatados. Si bien, tal como propone Levey (2014), ambas identifican al terreno de la subjetividad como clave para pensar en las memorias de las generaciones, para Hirsch lo que prima frente a la distancia generacional es la "conexión personal profunda", sus identificaciones, los lazos filiatorios.

Ciancio (2013) también debate este concepto y su aplicación para pensar en las situaciones del Cono Sur. Señala la dificultad implicada en distinguir entre quienes son testigos directos y quienes indirectos. Esto implica considerar la vivencia de los hijos como totalmente al margen de la experiencia de los padres y una herencia de recuerdos cuyo origen es básicamente mediado. La autora rescata los recuerdos propios de aquellos niños y niñas, lo cual pone en discusión la estructura de transmisión propuesta por Hirsch. Asimismo, Llobet (2015) realiza una crítica al abordaje en términos "posmemoriales" y también en lo que respecta a la caracterización de "generación posdictadura". Señala que en esta noción se configura sobre una idea del "concernimiento legítimo" a brindar testimonio y tiene como consecuencia la configuración de una "segunda generación testimoniante". A la vez, circula en ella una idea sobre la jerarquía de la experiencia, sobre quiénes son los principales actores de un fenómeno histórico. Para Llobet, los niños y niños de entonces fueron un objetivo central para las políticas culturales y educativas de los gobiernos dictatoriales. Las políticas que llevaron adelante intentaron modelar a los nuevos ciudadanos distanciándose de los supuestos "enemigos" de la nación. Esto implica, para la autora, rever los supuestos de la mediación adulta acerca de la experiencia de lo político en la infancia (reparando en la dimensión cotidiana e íntima de dicha experiencia) y con ello reconsiderar las arraigadas consideraciones que separan de manera taxativa el mundo infantil del adulto.

La reflexión que boceto aquí, se encuentra más lejos de examinar las características de verdad histórica o juridicidad que asumen los relatos de los "hijos e hijas" (Vezetti, 1996) y más cerca de recuperar la dimensión ética que hacen emerger las preguntas de aquellos niños y niñas que revisitan el pasado dictatorial (Llobet, 2016; 2015). Desde esta última perspectiva subrayo la relevancia de atender a las tramas afectivas y vinculares que hacen a la experiencia infantil. Esta mirada dialoga con la línea de Bjerg (2012) quien rescata en los relatos de niños y niñas migrantes la dimensión de lo pequeño, la hondura afectiva que entretejen los tránsitos.

Los recuerdos se ofrecen como un espacio de revisita, resultado de las experiencias y elaboraciones singulares y a la vez, de la interacción con otros: sociedad, grupos de pertenencia, medios de comunicación, escuela, familia. Algunas son formas colectivas del recuerdo y otras surgidas intersubjetivamente, configurando "comunidades de memoria" (Fried, 2016). Estos "Otros", siempre presentes en la actividad del recuerdo, pueblan y configuran un contexto histórico, político, social y cultural, que habilita determinados relatos y escuchas.

Los recuerdos de infancia, suponen la emergencia de formas memoriales diferentes a las adultas. Memorias que proponen otras experiencias e interpretaciones sobre su propia posición y la de los adultos en épocas pasadas. Así, se recuperan las simientes de muchas preguntas que configuran una identidad y una subjetividad singular. Recobrar dichas memorias implica posicionar a aquellos pequeños actores, como parte de una temporalidad compartida del exilio (Dutrenit, 2015) con voz propia y también protagonista de los acontecimientos, dejando de ser únicamente pasivos acompañantes de tránsitos. 


\section{Infancia y dictadura}

El exilio se impone en tanto acontecimiento que, en términos de Das (1995), hace parte de las formas de violencia social ejercidas por la represión dictatorial. Como evento crítico, desarticula la cotidianeidad, establece un quiebre y un extrañamiento respecto al mundo conocido. Según esta autora (2007), la violencia política no cesa cuando se detiene: se sigue desarrollando en el ámbito cotidiano y en las maneras de habitar la vida ordinaria. Las experiencias de violencia son naturalizadas, absorbidas, modulando las maneras en que se desarrollan los vínculos, las relaciones entre los sujetos y entre ellos y el mundo que los rodea. Das pone en tensión la idea de que los acontecimientos violentos tienen efectos observables por su carácter de comportamiento patológico, como por fuera de lo "normal". La noción de lo "normal" está aquí cuestionada, entendiendo que aquello "normal" también se constituye por los acontecimientos violentos del pasado.

A su vez, la infancia, tal como señala Llobet (2015), es un territorio clave en la disputa entre reproducción y transformación del orden social. Como también la dimensión memorial en tanto lugar de conflicto por los sentidos sociales que asume el pasado. En este sentido, me interesa considerar ambos espacios de disputa social que se conjugan en la recuperación de los recuerdos de la infancia. Otros relatos diferentes a los adultos comienzan a ser visibilizados, otras interpretaciones consideradas "menores" en el relato colectivo, así como las miradas sobre las dinámicas y las decisiones familiares en las que se encontraron inmersos.

Los gobiernos dictatoriales también han participado activamente de la disputa por significar a la infancia. Mediante políticas educativas y culturales, han intentado configurar un modelo de niño, consecuente con los principios que sostenían. Para el caso argentino (Osuna, 2017) durante la dictadura, los niños y niñas eran asociados con el "futuro", como un terreno incierto que por ello era clave controlar. Los contenidos educativos basados en principios nacionalistas y católicos, permitirían hacer de estos niños y niñas futuros ciudadanos en línea con la matriz promovida por los gobiernos dictatoriales. Según Osuna, para dichos gobiernos, el "virus subversivo" era la razón de la crisis de las familias. Eran los niños, los más débiles receptores de este "virus" y a la vez, los ungidos continuadores de la patria. El espacio familiar fue también un lugar de vigilancia, en el cual latían discursos y prácticas amenazantes para el orden social.

En este contexto, el exilio (Jensen, 2011; Lastra, 2014) como estrategia represiva durante las dictaduras también tuvo a niños y niñas como protagonistas. Exiliarse implicó para las familias, con diversos compromisos ideológicos y de militancia política, desgarros, desarraigos, incertidumbres, reconfiguraciones materiales e identitarias. A la vez, tuvieron diversas experiencias en cuanto a la figura de infancia con las cuales tuvieron contacto, fueron formados y educados. Los niños y niñas que formaron parte de los tránsitos exiliares, también debieron reconfigurar su pertenencia y sus pertenencias, convivir con otras dinámicas y personas, redefinir las familias, integrar nuevos lenguajes, nuevos códigos culturales. A su vez, muchos convivieron con la ansiedad de las posibles vueltas, con las nostalgias de sus padres y con la vivencia dislocada de pertenecer sin haber vivido en los lugares de sus orígenes.

\section{Espacios, territorios y pertenencias}

Pensar la experiencia del exilio en la infancia propone un nudo clave, al parecer, sobre la vivencia entre lo propio y lo ajeno. Para ingresar en ese terreno, la dimensión espacial brinda desde su protegida trivialidad, un profundo escenario. Las casas se ofrecen y regulan su relación con los otros, a partir de sus puertas y ventanas. Aquello que se permea de afuera a adentro, de adentro a afuera, estableciendo vínculo particular.

Puget (2000) reflexiona sobre los sentidos de pertenencia, las formas de vínculo que asumen a partir de la relación con los Otros. Ahonda sobre la cuestión del vínculo entre la reciprocidad y alternancia de los unos y de estos "otros", que pueden encarnarse en las figuras de alter o un ajeno. El primero presenta una diferencia compatible y el segundo, una forma de reconocimiento de la diferencia que es radicalmente incompatible. De este modo, según Puget, el Otro sigue siendo Otro en la medida en que conserve alguna de estas cualidades. Ahora bien, para la autora, es la posibilidad de estar dentro de ese vínculo lo que denomina el "sentido de pertenencia a un contexto". ¿Qué significa entonces pertenecer? ¿Cómo son las huellas del sentido de pertenencia en la infancia? Puget entiende que en "el pertenecer" intervienen tanto el hecho de "formar parte" de un conjunto y la de "apoderarse, apropiarse de un lugar" y distingue así entre lo posesivo y lo referencial. Lo posesivo como representación espacial y lo referencial como un aspecto abstracto, como un ideal común.

En definitiva, comprende que el sentimiento de pertenencia es una "experiencia de estar con otro y tener un lugar en el conjunto, algo como ir estando-siendo con otro, sin que haya una razón específica para estar o ser con ese otro" (Puget, 2000: 463). Así, la pertenencia se encuentra involucrada en la constitución subjetiva y memorial: aquellos eventos que conforman la pertenencia que se inscriben en una historia, en un grupo, se confirman sobre la base de lo referencial o de lo territorial. El desarraigo se instala como una "lesión" de un componente estable de una ilusoria pero invariable pertenencia. ¿Cómo se configura esa ilusión estable de pertenencia? ¿Es el espacio un componente "estable" entre quienes han crecido entre desplazamientos?

El espacio, particularmente el habitar la casa, no trata únicamente de la vivienda sino de todas las actividades, sentidos y relaciones que allí se desarrollan. Es un modo de existir en el mundo (Manzo, 2003). La casa se propone 
además como una metáfora, como la garantía de sentirse a resguardo, el lugar de lo familiar. El término "hogar", funciona, en algún sentido, como forma de capturar la esencia de la experiencia en los lugares (Manzo, 2003: 49). Esta metáfora ve la residencia como un "paisaje arquetípico" relacionado con la protección, con el refugio, que entra algunas veces en tensión con la mirada literal del hogar en tanto residencia. Según Manzo, diversos estudios han abordado el espacio como parte del desarrollo identitario y presentan definiciones propias sobre este vínculo (fijación en un lugar, sentido del lugar, identidad del lugar). Son matices en torno al vínculo entre las personas y los lugares físicos, que enfatizan el carácter dialogal de este vínculo, en tanto proceso que involucra el ambiente y a la vez las dimensiones subjetivas de los individuos. En tanto proceso dinámico, la identidad va y viene entre echar raíces y desarraigarse (Chawla en Manzo, 2003: 52). En esta línea, las relaciones con los lugares se ofrecen como un medio a partir del cual los sujetos pueden expresar su manera de relacionarse y su identidad "envolvente". Los significados y relaciones que se establecen con los lugares reflejan el involucramiento de los sujetos y su creatividad en cuanto a los significados que son organizados.

En lo que sigue del texto, expondré algunas escenas vinculadas a la dimensión espacial de las experiencias de infancia puestas en relato. Especialmente me centro en aquellas que tienen como eje la figura del hogar, y que nos permiten ingresar en los sentidos que asume la pertenencia para los quienes fueron niños y niñas durante el exilio.

\section{Migas de pan: la memoria como retorno}

Los territorios, el "lugar propio", son también parte de la experiencia. Las ciudades, los barrios como las casas se vuelven biográficos, en la medida en que los anclamos a nuestra experiencia: "son lugares míos", de algún modo. En el ejemplo de Knez (2014), tanto "mi" viaje a París como el hogar de "mi” infancia operan no solamente como una declaración sino también "como un acontecimiento autobiográfico personal". El sujeto selecciona y puede estar implicado "cualquier" lugar que opere como una estructura organizativa del "lugar mío" (Knez, 2014). Para las experiencias que abordamos aquí, ¿es posible considerar "cualquier" lugar para considerarlo propio? ¿Cuáles son entonces los lugares "míos” que forman parte de la pertenencia? ¿Son todos territoriales? ¿Son lugares referenciales? ¿Son vinculares? ¿Hasta dónde son propios?

Chawla (2003) reúne diversos trabajos que abordan el vínculo de los adultos de hoy con los lugares de la infancia. Varias nociones (apego, afiliación, preferencia, sentido del lugar, arraigo) abordan este vínculo y desde ellas, Chawla propone ahondar en una idea central, que sostiene que los niños y niñas que se encuentran apegados a un lugar lo valoran no solamente por satisfacer necesidades físicas, sino por las cualidades intrínsecas que presenta. Esto se expresa también en el placer de revivir un lugar en la memoria y la nostalgia de su pérdida que atestigua lo duradero de ese enlace. En este sentido, resulta un desplazamiento de lo infantil, entendiendo que los "lugares" de infancia son, por metonimia, la propia infancia perdida ${ }^{4}$.Una modalidad interesante para conceptualizar la noción de "hogar" tiene que ver con la dimensión del movimiento (Ahmed, Nash, Ní Laoire, en Ní Laoire, Carpena-Méndez, Tyrrell y White, 2010), atendiendo también a las redes de conexiones y apegos que allí se desarrollan. Así, se configura el "hogar" como un concepto móvil y desde allí pueden pensarse los devenires de la pertenencia y los modos en que se articula con la experiencia infantil.

Entre quienes vivieron su niñez en el exilio, varios de los relatos coinciden en que el recuerdo viene, para volver a casa. Así relata L., quien recuerda su casa en Cuba. La casa que los alojó en el exilio argentino al llegar antes de cumplir un año. Después de 30 años ya viviendo en Francia, volvió a visitar a su familia, aún en Cuba. Con cierta maravilla y algo de extrañeza, rememora la experiencia inconsciente de poder guiar a su familia hacia el lugar de su infancia:

Y cuando vamos yendo de un lugar de La Habana, desde el cerro a un lugar, Miramar, que era el barrio donde vivíamos de chiquito, la cosa muy extraña era que andando el auto... cosa justamente por las cuestiones de la memoria, yo sabía el camino. Tenía treinta años: vas por acá y se cruza un túnel bueno, saliendo del túnel la rotonda a la derecha, bueno acá en la izquierda y la próxima a la derecha de nuevo. Como que ese camino, muchas veces, de volver a casa en auto, teníamos un citroën, un auto viejo cuando era chiquito. ¡Conocía el camino! ¡Sabía cómo volver a casa!

La sorpresa de haber preservado el camino en algún rincón del recuerdo también es mencionada por M., argentina que de pequeña vivió en clandestinidad y se fue a un exilio, también clandestino, de múltiples parajes y circunstancias. M. recuerda que, ya de adulta, hizo con su familia un recorrido en auto por todas las casas en las que vivieron y resalta que "a todas volví de memoria" sin ver las direcciones. Memorizar los caminos era la manera de referenciar la casa. También, forma parte de la estrategia para volver, sin dejar huellas ni registros de sus residencias, ante la amenaza de que su familia sea descubierta. No había, en aquel entonces, miguitas de pan. Y ante el riesgo de perderse en el bosque, la memoria protegió hasta hoy los caminos, del olvido.

Agradezco a Valeria Llobet los comentarios y la reflexión. 
P. nacida en Israel, a los cuatro años viajó con su familia argentina a Madrid, vía Lisboa. Retornó a la Argentina también durante su infancia, aunque ya más cercana a la adolescencia. En su relato, quebrado por la emoción del recuerdo, P. subraya tener intacta la referencia sobre cómo llegar a su casa de la infancia en Madrid y el camino para (re)encontrarse con su amiga de la escuela. De forma significativa se conservan algunos caminos cotidianos, y no otros. Aquellos que tuvieron un lazo afectivo, emocional. Aquellos que han dejado intactos los pasajes para un posible retorno: en el recuerdo y en el encuentro. Son los hogares de pertenencia, en su sentido amplio, los que se atesoran entre las dislocaciones de los desplazamientos.

Por otra parte, para quienes nacieron durante el exilio de sus padres y crecieron en otros países diferentes al de sus familias de origen, ¿cómo son los recuerdos sobre las calles de un país donde no se vivió? ¿Cómo se arma un lugar propio/mío, sin la vivencia territorial? ¿Cómo ser uruguayo sin re-conocer, las calles o cómo ubicarse? G. es israelí, uruguayo y argentino. En su caso, el orden de la vivencia no acompasa el orden de pertenencia. Sus padres, de origen uruguayo, después de exiliarse en Israel, se instalan en la Argentina. G. cuenta entre risas nostálgicas que "quería ser uruguayo y no me salía”. Recuerda el desfasaje de querer ser y no poder encontrar el camino a la casa de origen:

(No me salía) conocer las calles, una boludez, porque podés ser uruguayo y no... y haberte olvidado de cómo viajar en ómnibus, cómo ir de tal lugar a tal lugar... pero a mí me consternaba: ¿y si me preguntaban a mí? Y también, si me preguntaban acá (Argentina), alguien me pedía algún dato, alguna cosa u otra ¡y yo no sabía! Pero entonces, ¿uruguayo qué? Y...lo vivía...con trauma...

Recordar u olvidar los caminos, no quiebra el sentido de pertenencia para quien es parte del lugar. Pero para quien el recuerdo no le permite reponer el vínculo con el espacio, parece ser algo constitutivamente incompleto, una raíz frágil. ¿Se puede ser de un lugar sin conocer cómo volver? ¿Se puede desconocer lo que es propio? ¿Es igual el sentido de pertenencia cuando la referencia es territorial que cuando es comunitaria o familiar? Este lugar brumoso es, tal vez, para Bachelard la "casa onírica”, aquella que viene de más lejos, desde una inspiración más inconsciente que la preocupación por la protección. La "casa natal" se erige sobre la "casa onírica", la de la pertenencia, donde nos "perdemos" (2006: 116). ${ }^{5}$ El espacio corporiza, tal vez, las tensiones que supone la pertenencia, la herencia y lo ajeno. Mientras en los ejemplos anteriores prevalece el descubrimiento casi iluminado del recordar, aún, las maneras de llegar a sus casas; en este último es el descubrimiento de otro, el que pone en jaque la autenticidad de la pertenencia.

Esta perspectiva del hogar y sus desplazamientos, nos convoca a dar un paso más en la reflexión y considerar, tal como lo hace Ahmed (1999), las dislocaciones que produce el exilio político: tanto en términos espaciales como temporales. La experiencia pasada se asocia con un hogar que "es imposible habitar y ser habitado en el presente". Por lo tanto, la autora nos propone que la dinámica de salir o entrar a casa, supone siempre una cuestión de memoria y con ella, una fractura en la continuidad entre el pasado y el presente. Desde Poult subraya esta similitud entre la dinámica memorial y el habitar (salir y volver a casa). Como los recuerdos, podemos hacer volver los lugares familiares a partir de su evocación, ubicarlos en ese espacio original de comodidad. De este modo, Ahmed señala que los lugares se comportan igual que los recuerdos pasados, como recuerdos que se van y regresan (Buijs en Ahmed, 1999). Pero este regreso al hogar se vuelve una proeza imposible: "es imposible regresar a un lugar que se vivió como hogar, precisamente porque el hogar no es exterior a uno mismo, sino que está implicado en él” (Ahmed, 1999: 343). En los ejemplos notamos como la memoria resguarda los hogares subjetivamente implicados, permitiendo así recuperar el camino a la casa de la infancia. Si bien es inscribe en las pequeñas fisuras de la imposibilidad: de volver a habitar el "mismo" lugar, de volver al lugar siendo ya otro, de no ser habitado del mismo modo por lo familiar. ¿Cómo atrapar este vaivén de los recuerdos? ¿Cómo retornar en sentido pleno, a los lugares de la infancia? ¿Es esto posible? ¿Hay caminos indelebles que conducen a un lugar original?

\section{Las casas y el (im)posible retorno}

El lazo afectivo con los lugares y las casas de la infancia puede tener asociados aspectos positivos de protección, de abrigo y también aspectos negativos, rechazos. Para algunos significa una pertenencia familiar y para otros, una referencia atemorizante o frustrante, un "lado sombrío" de las relaciones con los lugares (Chawla en Manzo, 2005). Son aquellos lugares significativos a los que estamos apegados para bien o para mal. Por ello, "cualquier exploración del lugar como un fenómeno de experiencia directa debe preocuparse por toda la gama de experiencias a través de las cuales todos conocemos y hacemos lugares" (Relph en Manzo, 2005: 70).

Los vínculos con los espacios acompañan toda la biografía: se van transformando y configurando con el tiempo mientras que inciden en las maneras presentes de vincularse. Hay una dimensión temporal del significado del lugar, que va modificándose a lo largo de la vida, según la naturaleza de formas de habitar anteriores y los nuevos lugares actuales (Gustafson en Manzo, 2005). Para muchos adultos los lugares espaciales suelen revivir tanto las nostalgias

\footnotetext{
Sobre esta atmósfera, Calvino cuenta las reflexiones de Marco Polo al entrar en una ciudad desconocida e imaginar como suya, la vida de otros: "de aquel pasado suyo verdadero e hipotético, él está excluido; no puede detenerse; debe continuar hasta otra ciudad donde lo espera otro pasado suyo, o algo que quizá había sido un posible futuro y ahora es el presente de algún otro. Los futuros no realizados son sólo ramas del pasado: ramas secas" (Calvino, 2007).
} 
como los conflictos: "nos ubicamos inconscientemente en entornos conflictivos que nos permiten resolver conexiones emocionales no resueltas" (Marcus en Manzo, 2005: 106).

Así, G., uruguaya exiliada en Cuba, a los 4 años recuerda intensamente la vivencia en Cuba, país en el que vivió hasta su adolescencia, hasta su vuelta al Uruguay. G. relata sus experiencias con la emoción y la alegría de haber formado parte de un paisaje cálido en su naturaleza, en su forma de relacionarse, en el mundo posible que allí se gestaba. Es el lugar donde ubica su felicidad. El desacople de la pertenencia se produce entre el sentimiento del "lugar en el mundo" y la construcción del lugar habitado a través del desarraigo cuya decisión era un mandato mudo.

¿Cómo volver al lugar del recuerdo de felicidad? ¿Es posible no perder en los desplazamientos? ¿En qué medida el lugar de felicidad en la infancia, determina una forma de arraigo no solo al lugar, sino al tiempo pasado? ¿Ese es el hogar permanente? G. me habla casi sin respirar. Suelta, como quien desliza el portón de un dique contenido, una vertiente de palabras anudadas, apuradas. En la velocidad se cuela el ir y venir de la emoción, a través de sus ojos. El dolor dulce de los bordes de la pertenencia:

Hace poco le dije a una amiga: Cuba duele, pero al mismo tiempo me lleva, me transporta al lugar donde fui más feliz y nunca más volví a ser feliz acá. Porque siempre me siento como que soy como una extraña. El desarraigo para mí es brutal. No me interesa el dinero, no tengo casi nada material, todo lo regalo, si tú me decís: me gusta tu anillo, yo te lo regalo. Siento como que nada me ata y cuando he ido a Cuba en ese proceso de resolver y no saber qué va a pasar porque siempre viven como con lo que deciden por ellos, con el tiempo ahora lo puedo decir, vivo con esa sensación permanente, desprendida, como que siempre puede pasar algo. Me quedaron sensaciones.

Despojarse de los anclajes, como una vía de protección ante la herida latente de la pérdida, quizás, como quien se desprende de sus propiedades (¿desgajando lo propio?). Son sensaciones que perduran y que constituyen las formas de habitar el mundo, las cosas, los lugares. Al mismo tiempo, cuenta sobre la relevancia que tuvo para ella retornar a este lugar de la infancia feliz. La posibilidad de volver a Cuba le permitió reencontrarse con su pasado, recomponer "algo" que permitió, luego del viaje, habitar la idea de la maternidad y concebir a su hijo. También resalta, en la vorágine, las diferencias con su hermana en las formas de transitar o de recordar su pasado. Retornar al lugar de la infancia se convirtió en una necesidad para reencontrar el camino al "hogar" para "recuperarse". Al mismo tiempo, G. evoca en su recuerdo las palabras de su hermana sobre la experiencia de indefensión ante la presencia de un ciclón. Debieron "tirar de una puerta" ante la ausencia de sus padres por su deber de "trabajo voluntario". Se tensionan, así, los fragmentos de recuerdo que son iluminados por "aquellas" niñas de una misma familia. La experiencia de la desprotección en el hogar ante el ciclón que debían enfrentar en soledad, fue un recuerdo que intervino en la forma de habitar este lugar de la infancia. Las sombras que emergen de un lugar sereno se combinan con la posibilidad de retornar para recobrar el lugar, tal vez incompleto, de pertenencia. Este arraigo ilusorio, en términos de Puget, vuelve a traer la lesión de la pertenencia estable, los caminos truncos, tal como G. considera su trayecto en comparación al de su hermana.

También para L., uruguaya que nació en el exilio de sus padres en Francia, cuenta sobre el viaje de retorno al lugar de su infancia en París. Recuerda, no solamente las dificultades de la nueva vida parisina, sino también los efectos de la prisión política y las dinámicas de violencia intrafamiliar que vivió de pequeña. La violencia dictatorial y familiar, provocaron las múltiples mudanzas, las que cruzan el océano y las que se desplazan en la ciudad. L. recuerda la vuelta a sus lugares de infancia en la adultez y también asocia el viaje al París de su infancia como clave para "develar" aquellas huellas dolorosas de su pasado. Trazas de esos recuerdos que, retorno mediante, le fue posible hilvanar como pequeños retazos que habían sido desparramados en el silencio. A la vez, remarca L. con asombro, los desfasajes de las dimensiones y las escalas, las recordadas y las reencontradas.

R. también identifica el viaje a su lugar de la infancia como "movilizador". Exiliada de pequeña, a los 4 años en Suecia previa vida en Brasil, desde Uruguay, R. recuerda intempestivamente, alternando pasado y presente con gran velocidad. Su recuerdo quiebra en lágrimas, a modo de pequeñas descargas emocionales, desde el comienzo de la entrevista. En el ir y venir de las rememoraciones y reflexiones sobre el presente, relata su experiencia de retorno a Suecia a partir de un viaje. Estando allí deseó compartir con su madre esa vuelta al lugar que, como cuenta, las unió de una manera particular cuando su padre decidió volver solo al sur. Conservó en su recuerdo las postales suecas de la infancia.

Según G., nacido en Brasil, de familia de exiliados argentinos, volver a las tierras de su infancia es un viaje imposible. Pausado y reflexivo, G. refiere al lugar en que nació y creció hasta los 12 años, como un espacio "muerto":

Mi lugar está destruido, digamos. Mi infancia, como lugar, yo no voy a volver nunca más ahí a donde estuve... no es parte de mi historia ni va a ser nunca. Es un lugar que murió prácticamente. Puedo ir, he ido de visita a ver el barrio, pero la verdad no creo que le haga. Ya fueron, se van enterrando esos lugares que por ahí en alguien que... no sé, crece en el mismo lugar, por ahí va "ahh ¿te acordás de acá? Cuando venía, no sé, ¡a comprar caramelos!" Bueno, yo no. Yo eso no lo voy a vivir, eso es bien del desarraigo.

Así, asocia el desarraigo quizás al diálogo trunco, desajustado, con un otro que no llega a compartir la misma experiencia. Las pequeñas rutinas cotidianas configuran referencias, modos de pertenencia, de habitar los espacios 
de la infancia. La tensión arraigo/desarraigo es un punto de reflexión común por parte de los entrevistados. Para S., uruguaya exiliada en Argentina a los cinco años, el desarraigo está asociado al hecho de "formar familia". Piensa así, en subjuntivo: qué hubiera pasado si el exilio no hubiera acontecido, si la vida hubiera sido diferente quedándose en el Uruguay.

Y si, un poco nos jodió eso, esa parte del desarraigo de decir, tal vez si hubiéramos vivido allá, la vida hubiera sido otra cosa... pero, bueno, viste, después de más grandes pudimos entender que...si bien, digamos, en un momento lo vimos, digamos, como algo un poco egoísta de mi padre, de desarraigarnos, de venir y de arriesgarnos, de ponernos como un poco en riesgo ¿no?

En esta reflexión, pasado y presente quedan sin tocarse, flotando. En la hipótesis de "otra" historia propia, como parte del desarraigo. Se llena, a la vez, de atenuantes, de muletillas que se distancian de las certezas: de las sentidas, de las arriesgadas, de las decisiones tomadas. Otra vez es una pregunta trunca ¿la vida allá hubiera sido igual que la vida acá? Son los espacios los que permiten imaginar otras vidas. Esto nos recuerda al rasgo subjuntivo de los relatos que identifica Bruner (2013), aquél que refiere quiénes y qué podríamos haber sido. El relato debe arraigar en lo familiar porque después de todo, dice Bruner, su misión es darle extrañeza a lo familiar, transformar el indicativo en subjuntivo (p.27).

Las relaciones con el lugar dan cuenta de los procesos identitarios, de sus devenires. Así, entre los entrevistados se subraya la importancia de poder estar en vínculo con lugares donde pudieran ser ellos mismos y ahondar en quiénes son. Las experiencias de infancia definieron lugares de destaque en las biografías y según señala Manzo (2005), las historias de los participantes sugieren que sus relaciones con estos lugares constituyen un modo de tramitar su identidad en el mundo. Tal es así que varios de los entrevistados refieren de forma explícita a cómo un lugar particular "los hizo quienes son" y cómo su comprensión de sí mismos cambió a través de su relación con ese lugar.

"Aquello/as" niños y niñas del exilio configuran también una suerte de "trayectos espirituales" en los cuales se rinde tributo al pasado (Chawla en Manzo, 2003). De hecho, y en particular algunos de los entrevistados de origen argentino, condensan esta experiencia en la figura del "tour nostálgico" en la que se comprende, sin describir, la densidad de este viaje. De este modo, el vínculo con los lugares de la infancia se establece como espacio a los que se retorna: como una cita con el pasado que invita al reencuentro y a la reelaboración. Además de las modulaciones que presentan los vínculos con los espacios, a lo largo de las biografías, existe según Chawla, un tiempo de resistencia donde los lazos entre el mundo subjetivo y el material configuran una particular dinámica de cambio y de anclaje.

\section{Mudanzas salobres: nuevas pertenencias}

El deslizamiento por diferentes casas, implicó además la adaptación a diferentes espacios sociales y culturales, tanto dentro de los mismos países de residencia como entre los países por los que los niños y niñas de entonces, fueron transitando. Rakoff (1977) sostiene que las casas son "espacios liminales" que separan áreas de la experiencia. Propone considerar las casas en sus múltiples significados, como "símbolo multivocal": ¿Qué significa cambiar de casas? ¿Qué implicancias presenta para los sujetos cambiar de casas con diferentes anclajes culturales y socio económicos? Señala que las mudanzas pueden ser concebidas como señales de éxito o de fracaso, igual que la relación de posesión con el espacio (habitar un lugar prestado, alquilarlo, ser propietario).

A. recuerda su infancia en Paraguay. Nacida en Argentina, se instala con su familia allí, luego de vivir la clandestinidad, la pérdida de familiares cercanos, el miedo, la violencia dictatorial en primera persona. A. recuerda a sus vecinos en Asunción y la experiencia de desvanecer los bordes de las casas y sus condiciones socioeconómicas, para construir nuevos vínculos, nuevas familias. Recuerda el vínculo con la casa vecina donde "vivía una familia muy pobre" cuyas hijas fueron como sus hermanas. Con ellas compartían juegos, cuidados, baños y "se cruzaban" de casa siempre, sorteando las condiciones sociales.

R., una niña de seis años al salir urgida desde Uruguay, primero vivió en Buenos Aires con su madre, en diferentes casas. Luego (junto a su madre y la nueva pareja) se instalaron en Ecuador. R. recuerda con asombro el contacto con las mujeres indígenas ecuatorianas: sus coloridos trajes, sus largas trenzas azabaches. Como si hubieran cobrado vida desde el papel de los libros de historia. También señala el cambio en cuanto a los recursos con los que contó su familia de entonces, al llegar a Ecuador:

Cuando nos fuimos a Ecuador como que la situación económica cambió. De estar cagados de hambre en Buenos Aires pasamos a estar en Ecuador en un apartamento divino con una vista a la montaña, coso enorme. Yo tenía mi cuarto, mi hermana otro cuarto, un baño que era solo para nosotras... una casa enorme, así un dúplex. La casa más linda que vi en mi vida. Y él (el compañero de la madre) pasa a tener sueldo en dólares, coso no sé qué y la agencia le pagaba la educación también y ahí me mandan a mí a un colegio privado que es el mismo que iban a ir estas amigas y todo eso. Ahí en Ecuador había empleada, de pronto apareció una empleada con cama, una ecuatoriana. 
M. debió acomodarse a diferentes situaciones culturales y de acceso a recursos o a condiciones materiales, en los múltiples tránsitos de la clandestinidad y el exilio desde argentina. Mudarse de casa determinó no solamente una vida en un nuevo barrio, ciudad o país, bajo la observancia (muchas veces) del secreto. También implicó acomodarse a una nueva vida por las nuevas condiciones que se presentaban. Las casas configuraban una nueva realidad social a la que aquellos niños y niñas debían adaptarse: tanto en los recursos disponibles, los espacios de intimidad, las condiciones de las viviendas, los nuevos vecinos con nuevas costumbres:

Pasabas de vivir, como en distintas condiciones sociales. Porque, ponele, la casilla de La Reja, era...tengo fotos en algún lado, era una casilla de madera verde, el techo era de chapa, de esa chapa, la que es además de cartón y brea que se agujerea de nada y se llovía por todos lados, y ¡no teníamos nada! Era re... todo el contexto era re humilde, era todo bien pobre, como eran las villas de aquella época. No había nada, ni nada, no había televisor, nada, no tengo el más mínimo recuerdo de nada de eso.

Luego, junto a su familia, y después de un trayecto por diferentes países, M. llegó a Cuba, donde cambiaron las condiciones de la casa donde vivieron por "una casa con tres habitaciones gigantescas, comedor, living, terraza, cuarto de servicio, cocina...", lo que implicó un nuevo ajuste tanto al país, a sus posibilidades de hablar de sí mismos sin cuidarse, a los contextos y vecinos del entorno, a las condiciones residenciales más confortables y recursos disponibles.

Por su parte, G. detalla la vida en Brasil y las dificultades que se le presentaron a partir de la separación de sus padres, exiliados argentinos allí. Brasileño de nacimiento, recuerda la tensión entre los espacios sociales de pertenencia de su padre y de su madre:

Nosotros empezamos a frecuentar la casa de mi viejo los fines de semana, como típico arreglo de separación (...) y tenía un statu quo muy distinto al nuestro entonces. Lo de la doble vida era de vivir ya te digo, cerca de las villas y después vivir en uno de los barrios más caros que era donde vivía mi viejo. Vas a comer a restaurantes todo el fin de semana y después, con mi vieja, estábamos alambrando para poder llegar a fin de mes, más o menos. Y lo del idioma, eso tanto en lo económico y en lo social también porque el entorno en donde se manejaba mi viejo era como medio votantes de Bolsonaro, para nosotros era un lugar así, fuera de lo que nos gustaba o queríamos estar, pero como hijos y niños teníamos que vivirlo. Era el lugar donde nuestro viejo había decidido vivir.

Así, cuenta sobre las orillas de los espacios sociales, tanto residenciales como ideológicas con los que debía convivir y adaptarse en código y recursos, en cada casa y caso. Estar "fuera de lugar" implica no solamente una característica inoportuna, sino también la dislocación de estar en el lugar y en el margen, al mismo tiempo. Las identidades y los vínculos filiales se desarrollan en este recuerdo, y en otros tantos, en espacios residenciales, políticos y culturales con determinadas características.

¿Qué lenguajes disponemos para pensar la subjetividad y la pertenencia? pregunta Berenstein (2006). Según el autor, no parecemos disponer de un lenguaje que no sea un "lenguaje propietario", donde se piensa al "yo" como propio, de mi propiedad, que me apropio y al otro, como no propio. Señala las diferentes pertenencias como las de parentesco o las de clase social y la relevancia de considerar estas últimas también para analizar los conflictos derivados de la pertenencia social, en tanto considerados (por los analistas) como aspectos "establecidos", "dados".

En los relatos, cambiar de casa tuvo otras implicancias. No solo significó cambiar sus rasgos edilicios, significó desarrollar una particular plasticidad a nuevos entornos, modalidades de vida, lenguajes, códigos, accesos. Los contextos socio-políticos también atraviesan la relación con los espacios, y para acercarse a los vínculos afectivos con los mismos, es importante atender a las implicancias políticas de esta relación. Estas ligazones con el espacio, y sus anclajes políticos, de algún modo, tienen su impacto en los lugares donde las personas se encuentran a sí mismas y dónde cada uno se siente pertenecer (Manzo, 2005: 54). Podríamos pensar en cómo diferentes amarres territoriales, sociales, políticos y también económicos, forman parte de la experiencia de las mudanzas durante la vida exiliar infantil.

\section{Pequeñas escenas de gestos domésticos}

Berenstein (2006) señala aquello "incierto" que se produce como experiencia emocional en el encuentro con "otro", como un momento de dislocación, que intenta ser formalizado o ritualizado. ${ }^{6}$ Se podría pensar en estas ritualidades asociadas a las mudanzas y a los momentos de incertidumbre que suponen los espacios y tiempos de tránsito, a la fragilidad de las explicaciones.

Dos relatos ilustran estos esfuerzos. El primero, el de Á. P., uruguayo que huyó a los ocho años, clandestino con su madre y hermana de Montevideo para la Argentina. Á. P. relata el momento en que secuestraron a su madre y a su hermana embarazada y el tiempo en el cual estuvieron desaparecidas, sin saber dónde y cómo estaban. Durante esas

(Y propone como ejemplos de ello al lenguaje jurídico y el religioso). 
dos semanas que desaparecieron a su madre y su hermana, Á. P. siguió yendo a la escuela. Continuar con la rutina pese al horror de la incertidumbre es un gesto en la mantención de una dinámica cotidiana. Es, al decir de Das (2012), un esfuerzo por mantener la vida cotidiana en condiciones de fragilidad y vulnerabilidad. De camino a la escuela recuerda pasar por la seccional policial. En el camino de todos los días, conviviendo con el terror, encontró dentro de sí una pequeña rendija interior por la cual enfrentarse a la violencia:

De hecho, desde el día uno que se llevaron a mi vieja yo seguí yendo a la escuela, iba caminando solo, esas seis cuadras, siete cuadras y pasaba por la seccional de policía, y para mí estaba ahí en mi imaginario de gurí. Entonces yo pasaba, miraba y iputeaba para adentro!, me acuerdo clarito, a la ida y a la vuelta. Puteaba ¡milicos de mierda, no sé cuánto, suéltenla!, pero, claro, imposible que estuvieran ahí porque si no hubiera sido mucho más fácil. Para mí no había otra policía, la policía era esa (...), pero era consciente también en esos días que no conté nada a nadie... no se podía contar nada a nadie en la escuela. Esos 15 días yo seguí yendo y nadie me dijo nada, nadie me habló nada y no me acuerdo de haber hablado con nadie. Ni la maestra, ni si necesitaba contención o algún tío que haya dicho: "mirá que está pasando esto". Nada.

Esta defensa del cotidiano ante la fractura de lo acontecido supone, además, en el recuerdo de Á. P., la imposibilidad de poner en palabras lo incomprensible, lo incierto que arrastra la violencia. El silencio, la ausencia de explicaciones o de contención adulta, propone un abanico de preguntas: ¿Por qué se sostuvo el silencio? ¿Pudo ser el silencio una táctica de resistencia? ¿De protección? ¿Tal vez se asumía que los niños y niñas no comprendían los acontecimientos?

El segundo, el relato de M., quien recuerda el modo en que sus padres convertían cada casa en un hogar. En el esfuerzo de mantener la dinámica y el sentido de lo cotidiano en tiempos donde acechaba la violencia, M. destaca los detalles de los objetos, las decoraciones de las casas para volverlas propias:

Entonces mi papá, siempre, y mi mamá, llegábamos a una casa y la hacían, la reconstruían toda y acomodaban todo y ponían muebles y cositas, todo, hacían como un hogar inmediatamente, y estantecitos. Mi papá siempre hacía cosas manuales, arreglaba las ventanas, todo y hay cosas, hay algunas cosas que yo veo que se repitieron a lo largo de las casas y se repiten hasta el día de hoy en la familia, que vos mirás las casas y todas nuestras casas tienen tipo, tener la repisa sobre la mesada, esa es una cosa re de mi papá, ¡con todos los frasquitos acomodados! (risas) Lo tuvo mi hermana, lo tuve yo, todas cosas así, lo tiene él, lo tiene mi mamá. Sí, enseguida ponían cosas en la casa. La casa nunca parecía una casa de paso, no. Hacían cosas para vos y eso.

Retomo aquí las nociones de Das (2012) en lo relativo a los trabajos de reconstitución de la vida cotidiana, a los esfuerzos por sostener las condiciones de la pertenencia y de contener los efectos flotantes de la incertidumbre. Son las pequeñas re-construcciones, los gestos entrañables por mantener un hogar, pese a las dificultades imbricadas en los desplazamientos. Se configura una suerte de hábito familiar en el que se adaptan los espacios a partir de los arreglos, de los objetos, de la ligazón con lo material que produce un sentido de familiaridad, de relación afectiva con el espacio ${ }^{7}$. Así también el gesto de afecto como parte de la relación amorosa con sus padres "hacían cosas para vos". Según Latour, más que "decorado," los objetos despliegan un vínculo que imprime determinadas formas de significar y de actuar (Latour, 2008: 125). Lejos de ser "casas de paso", en cada una de ellas se imprime el trabajo de hacer de cada vivienda, un lugar donde "sentirse en casa".

\section{Para el cierre}

En este texto, intenté recuperar algunas escenas en que convergen los relatos, que articulan espacio y pertenencia en la experiencia exiliar durante la infancia. Aquello que se conserva en el recuerdo es producto, también, de la conexión afectiva que se liga a esa rememoración. En este sentido, los espacios se tornan significativos en tanto marcadores de transiciones, como símbolos de eventos contundentes dentro de las biografías. Se establecen como puntos de referencia en un vínculo significativo o en simples momentos de reflexión (Manzo, 2003: 53). Así, Ahmed (1999) propone pensar el acto de recordar, entre aquellos que han migrado, como una incomodidad, un sentirse "fuera de lugar", una falla que se experimenta en el habitar: entre lo familiar y lo extraño, entre el pasado y el presente.

Los rastros de la violencia en los bordes del hogar, las mudanzas forzadas, los desmembramientos familiares y comunitarios, modulan la experiencia. Contemplé aquí la dimensión de la pertenencia, las dislocaciones, los sentidos del arraigo en la memoria, las transformaciones y los esfuerzos de preservación del hogar, que forman parte de los recuerdos sobre los múltiples tránsitos del exilio. Esta vivencia de la infancia "entre hogares" configura, tal como señala Ahmed, los contornos de un espacio de pertenencia, que podríamos abordar como en incompleta construcción. Tanto los recuerdos detenidos, los silenciados, los retornados, los imposibles, los preservados, los descubiertos, for-

(No es casual aquí recurrir a diminutivos para describir aquello que torna hogar a una casa: objetitos, estantecitos, frasquitos). 
man parte de retazos que van modificando sus figuras. Se zurcen invisibles, en la subjetividad, modos de arraigarse y desarraigarse, de vincularse a los espacios. Modos de habitar lugares y vínculos.

Pretendí aquí proponer una reflexión abierta sobre la dimensión espacial en las memorias de las infancias que experimentaron el exilio durante las últimas dictaduras, y esbozar algunas preguntas que desde allí se despliegan. Las trazas saladas de las casas de los niños y niñas que vivenciaron el exilio, permiten tal vez, adentrarnos en algunos sabores que van dejando las experiencias en la memoria y en la identidad.

\section{Referencias bibliográficas}

Ahmed, S. (1999). Home and away: Narratives of migration and estrangement. International journal of cultural studies, 2(3), 329-347. https://doi.org/10.1177/136787799900200303

Alberione, E. (2018). Narrativas contemporáneas de los exiliadxs hijxs: esa particular manera de contar-se. En M. S. Lastra (coord.), Exilios: un campo de estudios en expansión. Colección Grupos de Trabajo. Ciudad Autónoma de Buenos Aires: CLACSO (en línea). http://biblioteca.clacso.edu.ar/clacso/gt/20180803013456/Exilios.pdf

Arfuch, L. (2018). La vida narrada. Memoria, subjetividad y política. Villa María: Eduvim.

Basso, Ma. F. (2016). Volver a entrar saltando: Memorias visuales de la segunda generación de exiliados políticos en México. Universidad Nacional de La Plata, Facultad de Humanidades y Ciencias de la Educación. Tesis para optar al grado de Magíster en Historia y Memoria (en línea). http://www.memoria.fahce.unlp.edu.ar/tesis/te.1341/te.1341.pdf

Bachelard, G. (2000). La poética del espacio. Argentina: Fondo de Cultura Económica.

Basile, T. (2019). Infancias: La narrativa argentina de HIJOS. Villa María: Eduvim.

Berenstein, I. (2006). El sujeto y sus vínculos: un mundo de posibilidades. Trabalho apresentado na Jornada Anual do Contemporâneo: Instituto de Psicanálise e Transdisciplinaridade, Porto Alegre, Brasil (en línea). http://www.revistacontemporanea. org.br/revistacontemporaneaanterior/site/wp-content/artigos/artigo 70.pdf

Bertaux, D. (1999). El enfoque biográfico: su validez metodológica, sus potencialidades. Proposiciones, 29(4), 1-23.

Bjerg, M. (2012). El viaje de los niños. Inmigración, infancia y memoria en la Argentina de la Segunda Posguerra. Buenos Aires: Edhasa.

Bruner, J. (2013). La fábrica de historias, Derecho, literatura y vida. Buenos Aires: Fondo de Cultura Económica.

Calvino, I. (2007). Las ciudades invisibles. Editorial Siruela.

Chawla, L. (2007). Childhood experiences associated with care for the natural world: A theoretical framework for empirical results. Children Youth and Environments, 17(4), 144-170 (en línea). https://www.jstor.org/stable/10.7721/chilyoutenvi.17.4.0144

Ciancio, M. B. (2013). ¿Las víctimas como precio necesario?, Congreso Internacional Centro de Ciencias Humanas y Sociales-CSIC, Center for Human and Social Sciences-CSIC (en línea). http://www.proyectos.cchs.csic.es/fdh/sites/default/files $/ 2-2 \% 20$ Ciancio.pdf

Daona, V. (2017). Las voces de los/as hijos/as de desaparecidos/as en Argentina: un género. Universidad Nacional del Litoral. Facultad de Humanidades y Ciencias. Centro de Investigaciones Teórico-Literarias. El Taco en la Brea; 4; 6; 12-2017; 37-55 (en línea). http://hdl.handle.net/11336/46213

Das, V. (2012). Ordinary ethics: The perils and pleasures of everyday life. En A Companion to Moral Anthropology (pp. 133-149), edited by Didier Fassin. New York: Wiley-Blackwell.

Das, V. (1995). Critical events: an anthropological perspective on contemporary India (Vol. 7). Delhi: Oxford University Press.

Delory-Momberger, C. (2012). Abordagens metodológicas na pesquisa biográfica. Revista Brasileira de Educação, 17(51),523536. https://doi.org/10.1590/S1413-24782012000300002

Dutrénit Bielous, S. (2015). Aquellos niños del exilio. Cotidianidades entre el Cono Sur y México, México: Editorial Mora.

Fried, G. (2016). Trauma social, memoria colectiva y paradojas de las políticas de Olvido en el Uruguay tras el terror de Estado (1973-1985): memoria generacional de la post-dictadura (1985-2015), ILCEA, 26 | 2016. http://journals.openedition.org/ ilcea/3938

Hirsch, M. (2008). The generation of postmemory. Poetics today, 29(1), 103-128. https://doi.org/10.1215/03335372-2007-019

Jelin, E. (2009). Género y familia en la política pública: una perspectiva comparativa Argentina-Suecia. Interseçoes: Revista de Estudos Interdisciplinares, 35-55.

Jensen, S. (2011). Exilio e Historia Reciente: Avances y perspectivas de un campo en construcción. Aletheia, 1(2) (en línea). http://www.memoria.fahce.unlp.edu.ar/art_revistas/pr.4806/pr.4806.pdf

Kaiser (2005). Postmemories of Terror. Pallgrave Macmillan: New York.

Knez, I. (2014). Place and the self: An autobiographical memory synthesis, Philosophical Psychology, 27: 2, 164-192. DOI: $10.1080 / 09515089.2012 .728124$

Lastra, S. (2014). Los retornos del exilio en Argentina y Uruguay: Una historia comparada de las políticas y tensiones en la recepción y asistencia en las posdictaduras (1983-1989). Tesis de doctorado. Universidad Nacional de La Plata. Facultad de Humanidades y Ciencias de la Educación (en línea). http://www.memoria.fahce.unlp.edu.ar/tesis/te.1002/te.1002.pdf

Latour, B. (2008). Reensamblar lo social. Bs. As: Manantial.

Levey, C. (2014). Of HIJOS and Niños: Revisiting Postmemory in Post-Dictatorship Uruguay. History \& memory, 26(2), 5-39.

Llobet, V. (2015). “Y yo, ¿dónde estaba entonces?”. Infancia, memoria y dictadura. Horizontes Sociológicos, (5), 46-57 (en línea). http://aass.org.elserver.com/ojs/index.php/hs/article/view/28 
Llobet, V. (2016). Eso era lo normal Ser niño en dictadura: un debate sobre la subjetividad y la política. Entramados y Perspectivas, Vol. 6, Núm. 6 (en línea). http://publicaciones.sociales.uba.ar/index.php/entramadosyperspectivas/article/view/1655.

Logie, I., Willem, B. (2016). Narrativas de la postmemoria en Argentina y Chile: la casa revisitada. Alter/nativas, (5), 1-25 (en línea). http://hdl.handle.net/1854/LU-5638150

Manzo, L. C. (2003). Beyond house and haven: Toward a revisioning of emotional relationships with places. Journal of environmental psychology, 23(1), 47-61. https://doi.org/10.1016/S0272-4944(02)00074-9

Manzo, L. C. (2005). For better or worse: Exploring multiple dimensions of place meaning. Journal of environmental psychology, 25(1), 67-86. https://doi.org/10.1016/j.jenvp.2005.01.002

Ní Laoire, C., Carpena-Méndez, F., Tyrrell, N., White, A. (2010). Introduction: Childhood and migration mobilities, homes and belongings. Childhood, 17(2), 155-162. https://doi.org/10.1177/0907568210365463

Ocampo, S. (1982). La furia y otros cuentos. Madrid: Alianza.

Osuna, M.F. (2017). Políticas de la última dictadura argentina frente a la "brecha generacional". Revista Latinoamericana de Ciencias Sociales, Niñez y Juventud, 15(2), 1097-1110 (en línea). http://www.scielo.org.co/scielo.php?pi$\mathrm{d}=\mathrm{S} 1692-715 \mathrm{X} 2017000200021 \&$ script $=$ sci_abstract\&tlng $=\mathrm{pt}$

Paiva, V. (2018). Scenas de la vida cotidiana. Metodología para comprender y disminuir la vulnerabilidad en la perspectiva de los derechos humanos. En A. Amuchástegui, J. Ayeres, A. Capriati, V. Paiva, M. Pecheny, Prevención, promoción y cuidado. Enfoques de vulnerabilidad y derechos humanos. Buenos Aires: Teseo.

Paiva, V. (2006). Analisando cenas e sexualidades: a promoção de saúde na perspectiva dos direitos humanos. En C. F. Cáceres, G. Careaga, T. Frasca, M. Pecheny, A. Piscitelli, A. Amuchástegui, J. Russo, Sexualidad, estigma y derechos humanos: desafios para el acceso a la salud en América Latina (pp. 23-51). Universidad Cayetano Heredia/Centro Latinoamericano de Sexualidad y Derechos Humanos.

Philo, C. (2003). 'To go back up the side hill': Memories, Imaginations and Reveries of Childhood. Children's Geographies, 1(1), 7-23. http://dx.doi.org/10.1080/14733280302188

Puget, J. (2000). Traumatismo social: memoria social y sentimiento de pertenencia. Memoria social-memoria singular. Psicoanálisis APdeBA, 32, 455-82 (en línea). https://www.apdeba.org/wp-content/uploads/022000puget.pdf

Rakoff, R. M. (1977). Ideology in everyday life:the meaning of the house. Politics \& Society, 7(1), 85-104. https://doi. org/10.1177/003232927700700104

Robin, R. (1989). Literatura y biografía. Historia y fuente oral, 69-85.

Ros, A. (2012). The Post-Dictatorship Generation in Argentina, Chile and Uruguay. Collective Memory and Cultural Production. New York: Pallgrave Macmillan.

Sarlo, B. (2005). Tiempo pasado. Cultura de la memoria y giro subjetivo. Una discusión. Buenos Aires: Siglo Veintiuno.

Scott, J. W. (2001). Experiencia. Revista de estudios de género: La ventana, 2(13), $42-74$ (en línea). https://dialnet.unirioja.es/ servlet/articulo? codigo $=5202178$

Serpente, A. (2011). The traces of "postmemory" in second-generation Chilean and Argentinean identities. En The Memory of State Terrorism in the Southern Cone (pp. 133-156). US: Palgrave Macmillan.

Suleiman, S. R. (2002). The 1.5 generation: Thinking about child survivors and the Holocaust. American Imago, 59(3), $277-295$.

Vezzetti, H. (1996). Variaciones sobre la memoria social. Punto de vista, 56(2). 